\title{
Impact of prior hospital mortality versus surgical volume on mortality following surgery for congenital heart disease
}

\author{
Matthew E. Oster, MD, ${ }^{\mathrm{a}}$ Matthew J. Strickland, $\mathrm{PhD},{ }^{\mathrm{b}}$ and William T. Mahle, $\mathrm{MD}^{\mathrm{a}}$
}

Objective: Our objective was to assess the relationships of a hospital's past adjusted in-hospital mortality and surgical volume with future in-hospital mortality after surgery for congenital heart disease.

\begin{abstract}
Methods: Using the Pediatric Health Information Systems database, we (1) calculated hospital surgical volume and standardized mortality ratio (= observed number of deaths/expected number of deaths adjusted for surgery type) for January 2004 through June 2006 for children (0-18 years) after surgery for congenital heart disease at 38 hospitals and (2) assessed the relationship between these values and subsequent mortality during July 2006 through December 2008. We constructed Poisson regression models to estimate risk of mortality, adjusting for age, race, sex, genetic syndrome, insurance type, and surgery type (using the Risk Adjustment in Congenital Heart Surgery method).

Results: There were 49,792 hospital encounters during 2004 through 2008 for pediatric patients having surgery for congenital heart disease, with an overall in-hospital mortality of $3.45 \%$. For the 24,112 eligible encounters during July 2006 through December 2008, a hospital's prior standardized mortality ratio was significantly associated with postoperative in-hospital mortality $(P<.0001)$, and a hospital's prior surgical volume had only borderline significance $(P=.0792)$. On stratified analysis, past standardized mortality ratio was associated with mortality for both lower- and higher-risk surgical risk categories $(P=.0105$ and .0015 , respectively). Hospital surgical volume was not significantly associated with mortality for lower-risk categories $(P=.4122)$, but it was borderline significant for higher-risk categories $(P=.0678)$.
\end{abstract}

Conclusions: In this data set, prior hospital surgical volume tended to be associated with improved mortality after higher-risk operations in pediatric patients with congenital heart disease, whereas prior hospital postoperative mortality was significantly associated with mortality across all risk strata of congenital heart surgery. (J Thorac Cardiovasc Surg 2011;142:882-6)

In the current health care environment, greater emphasis is now being placed on outcomes and quality. ${ }^{1}$ One key outcome that has been identified as a marker of the quality of a hospital is surgical mortality. ${ }^{2,3}$ Greater hospital surgical volume has been shown to be associated with lower inhospital mortality for a variety of operations in adults. ${ }^{4} \mathrm{Sim}-$ ilarly, many researchers have identified surgical volume as a significant predictor of in-hospital mortality after surgery for congenital heart disease. ${ }^{5-12}$ As such, some insurance companies are using hospital surgical case volume as part of a basis for determination of and referral to centers of excellence in surgery for congenital heart disease. ${ }^{13}$

However, these efforts have largely ignored the effect that a hospital's past in-hospital mortality may have on out-

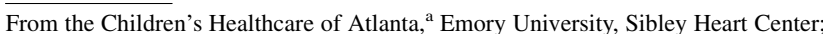
and Rollins School of Public Health, ${ }^{\mathrm{b}}$ Emory University, Atlanta, Ga.

Disclosures: Authors have nothing to disclose with regard to commercial support.

Received for publication Oct 19, 2010; revisions received March 24, 2011; accepted for publication April 11, 2011; available ahead of print May 16, 2011.

Address for reprints: Matthew E. Oster, MD, Children's Healthcare of Atlanta, Division of Pediatric Cardiology, 1405 Clifton Rd NE, Atlanta, GA 30322 (E-mail: osterm@kidsheart.com).

0022-5223/\$36.00

Copyright (C) 2011 by The American Association for Thoracic Surgery doi: $10.1016 /$ j.jtcvs.2011.04.011 comes. In a study of low-birth-weight infants, past hospital mortality was more important than past hospital volume in predicting future outcomes. ${ }^{14} \mathrm{We}$ sought to determine whether a similar relationship is true for congenital heart disease outcomes. We hypothesized that prior standardized in-hospital mortality ratio (SMR) is a significant predictor of future in-hospital mortality after surgery for congenital heart disease even after accounting for hospital surgical volume.

\section{METHODS}

\section{Data Source}

We used data from the Pediatric Health Information System (PHIS) database, a large, multi-center administrative database. ${ }^{15}$ Data are collected from pediatric tertiary care hospitals that are members of the Child Health Corporation of America. This organization offers a range of products and services to its member hospitals to reduce hospital costs, increase revenue, strengthen the competitive position of the hospitals, and improve the quality of care for children. To assist with these quality improvement efforts, member hospitals contribute data on demographics, diagnoses, procedures, interventions, and outcomes for all inpatient encounters.

\section{Patient Population}

We included in our analyses all children (aged 0-18 years) who underwent surgery for congenital heart disease from January 1, 2004, to December 31, 2008, at institutions that contributed to the PHIS database during the entire study period and that had at least 50 eligible encounters in the first 


\section{Abbreviations and Acronyms \\ ICD-9 = International Classification of Diseases, Ninth Revision \\ PHIS = Pediatric Health Information System \\ RACHS-1 = Risk Adjustment for Congenital Heart Surgery (method) \\ SMR = standardized in-hospital mortality ratio}

half of the study period. For each hospital encounter, we used International Classification of Diseases, Ninth Revision (ICD-9), codes to determine the highest risk category for that encounter using the Risk Adjustment for Congenital Heart Surgery method (RACHS-1). ${ }^{16}$ We excluded from our analyses encounters in which a RACHS- 1 category could not be assigned.

\section{Study Variables}

Patient variables that were collected included age, race (white, black, other), sex, presence of genetic syndrome (yes/no), insurance type (government, private, other), surgery risk category (using the RACHS-1 method), and discharge status (death vs other). Using the information from the PHIS database, we calculated hospital surgical volume and SMR (SMR $=$ observed number of deaths/expected number of deaths adjusted for surgery type) for January 2004 through June 2006 and July 2006 through December 2008 separately. To calculate a risk-adjusted SMR for each hospital, we first determined the overall mortality for each RACHS1 category across all hospitals; we then used these mortality estimates to calculate the expected number of deaths at each hospital given the number of particular RACHS-1 category cases at that hospital.

\section{Statistical Analysis}

In the first part of our analysis, we assessed the correlation between an institution's prior SMR or surgical volume with its future SMR. To do this, we calculated Spearman correlation coefficients among the hospital surgical volumes and SMRs from January 2004 through June 2006 with the hospital SMRs from July 2006 through December 2008. In the second part of our analysis, we estimated the risk of in-hospital mortality for children undergoing surgery for congenital heart disease during July 2006 through December 2008 by constructing generalized estimating equation Poisson regression models. We considered the institutional-level variables of hospital surgical volume and SMR from January 2004 through June 2006 as independent variables while adjusting for the patient-level variables of age, race, sex, genetic syndrome, insurance type, and surgery risk category (using the RACHS-1 method). Owing to small case counts for RACHS- 1 category 5, we combined this group with RACHS- 1 category 6 in our regression model. To evaluate whether the effects of surgical volume and SMR varied by surgical risk group, we performed stratified analysis by lower-risk (RACHS-1 categories 1, 2, and 3) and higher-risk (RACHS-1 categories 4, 5, and 6) subtypes. For this analysis, we calculated and used the specific risk-adjusted hospital SMRs and case loads for the lower-risk and higher-risk categories. Because several children had more than 1 surgical encounter, we used robust variance estimation in all of our regression models to account for the lack of independence. ${ }^{17}$ From these models we calculated adjusted risk ratios and $95 \%$ confidence intervals. All analyses were performed using SAS version 9.2 (SAS Institute, Inc, Cary, NC).

\section{RESULTS}

For the period of January 1, 2004, through December 31, 2008 , the PHIS database included 49,792 hospital encounters for congenital heart surgery at 39 children's hospitals, with an overall in-hospital mortality of $3.45 \%$. During January 2004 through June 2006, hospital surgical volume ranged from 9 to 1555 encounters (median 530), and SMR ranged from 0.49 to 3.22 (median 0.99). After excluding the 1 hospital with fewer than 50 encounters during the first half of the study period, there were 24,112 eligible encounters at 38 children's hospitals during July 2006 through December 2008 , with an overall in-hospital mortality of $3.21 \%$.

In univariate analysis, there was a positive relationship between a hospital's SMR from January 2004 through June 2006 and the subsequent SMR from July 2006 through December $2008(P=.0002)$ (Figure 1). Similarly, there was an inverse relationship between prior hospital surgical volume and subsequent SMR $(P=.0089)$. However, the linear relationship between prior SMR and subsequent SMR $\left(R^{2}=0.32\right)$ was notably higher than the linear relationship between prior surgical volume and subsequent SMR $\left(R^{2}=0.18\right)$.

We then conducted further analysis to investigate the associations of prior hospital SMR and prior hospital surgical volume with future patient mortality. Results from the generalized estimating equation Poisson regression models, with hospital surgical volume and SMR from January 2004 through June 2006 as independent variables while adjusting for age, race, sex, genetic syndrome, insurance type, and surgery type, are presented in Table 1. On average, for every 0.1-unit decrease in prior hospital SMR, there was a $3.4 \%$ decrease in the relative risk of inpatient mortality $(P<.0001)$. Prior hospital surgical volume was of borderline significance $(P=.0792)$, with an increase in surgical volume of 40 cases annually corresponding to a decrease in relative risk of inpatient mortality of $2.0 \%$.

In stratified analysis by RACHS-1 category, prior riskadjusted hospital SMR was significantly associated with future mortality for both lower-risk RACHS- 1 categories $(P=.0105)$ and higher-risk categories $(P=.0015)$. Prior hospital surgical volume was not significant for lower-risk categories $(P=.4122)$ but was of borderline significance for higher-risk categories $(P=.0678)$ (Table 2$)$.

\section{DISCUSSION}

In our study, prior hospital surgical volume was significantly associated with decreased postoperative mortality, a finding that is similar to the results of many prior studies. ${ }^{5-12}$ After adjusting for multiple factors including prior hospital surgical mortality, prior surgical volume tended toward significance for higher-risk operations for congenital heart disease but was not significant for lower-risk operations for congenital heart disease. Prior in-hospital mortality was significantly associated with future inhospital mortality after surgery for congenital heart disease across all risk strata, even after adjusting for multiple factors including prior hospital surgical volume. 

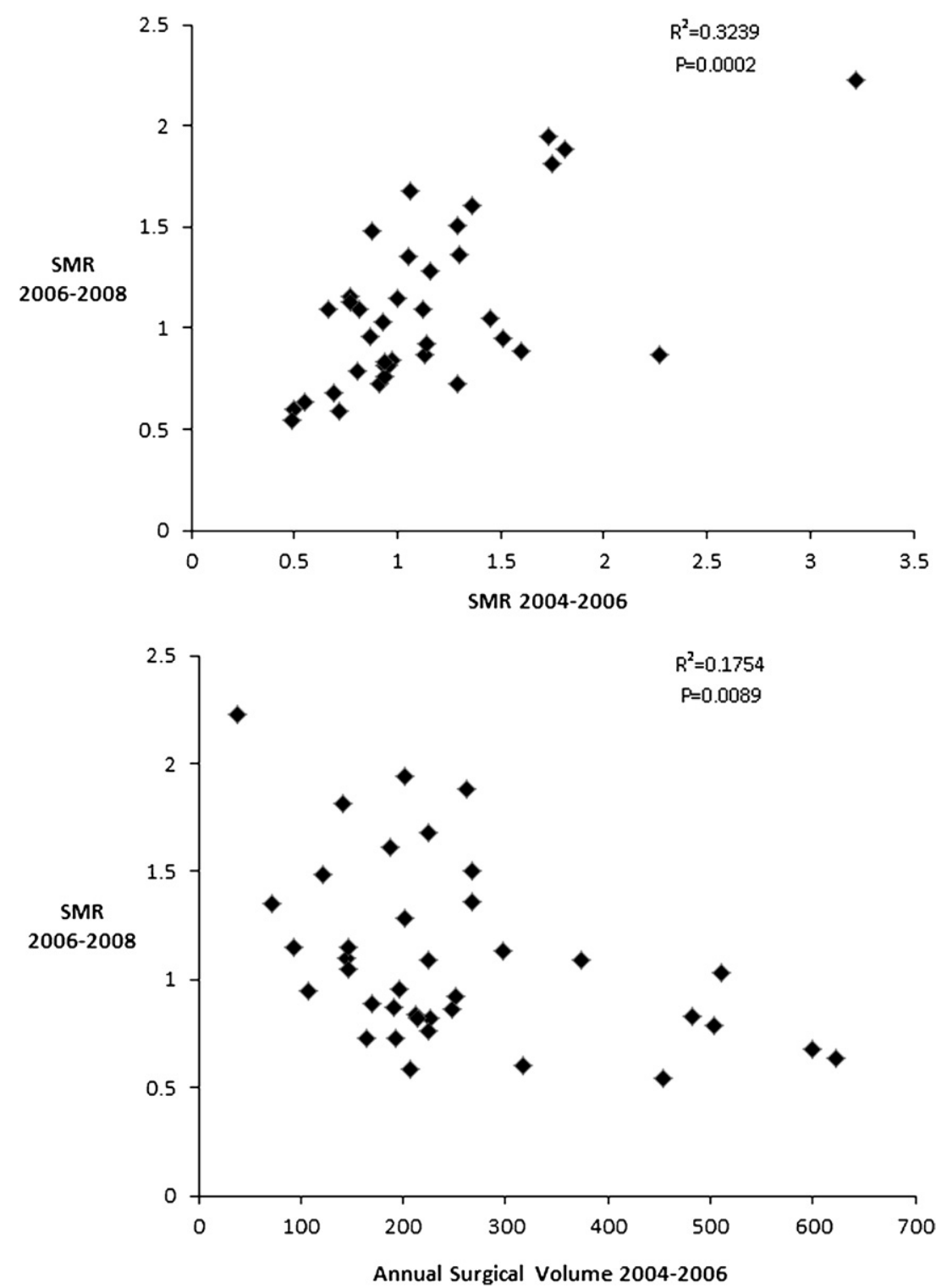

FIGURE 1. Relationship between July 2006-December 2008 standardized mortality ratio (SMR) and January 2004-2006 SMR or hospital surgical volume. SMR $=$ observed number of deaths/expected number of deaths adjusted for surgery type. All $R^{2}$ and $P$ values are from Spearman correlation.

What, then, are the factors that may be contributing to an improved prior mortality in those hospitals with a lower surgical volume? There may be factors that hospitals that perform more higher-risk operations are more likely to implement. For instance, such hospitals may be more likely to have a dedicated cardiac intensive care unit, standardized postoperative protocols, and 24-hour in-house attending coverage. If these factors are important and low-volume hospitals were also to institute these measures, this may explain why surgical volume fails to meet significance when prior mortality is included in our models, particularly in the lower-risk surgical categories. That is, smaller volume hospitals may be able to attain mortality rates similar to those of large volume hospitals by instituting important quality improvement measures. Further research to elucidate these factors is certainly warranted.

Currently, hospital surgical volume is used as an important criterion for referral for pediatric patients with congenital heart disease to improve quality of care. This method of referral has been shown to be associated with improvements in mortality, ${ }^{18,19}$ and our findings agree with a prior study that suggests that this referral model may be appropriate for higher-risk cases. ${ }^{20}$ However, some have questioned this approach and have proposed that past quality should lead to higher volume, not the other way around. ${ }^{21,22}$ On the basis of our findings, prior hospital mortality may be an appropriate consideration in the referral process. Such a system would reward those hospitals that focus on 
TABLE 1. Factors associated with in-hospital mortality after surgery for congenital heart disease, July 2006-December 2008

\begin{tabular}{|c|c|c|c|c|}
\hline \multicolumn{2}{|c|}{ Institution-level variables } & \multicolumn{2}{|c|}{$\begin{array}{l}\text { Relative change in mortality per increase of } \\
40 \text { cases annually }(95 \% \mathrm{CI})^{*}\end{array}$} & $P$ value \\
\hline \multicolumn{2}{|c|}{ Surgical case volume, January 2004-June 2006} & \multicolumn{2}{|c|}{$-2.0 \%(-4.1,0.2)$} & .0792 \\
\hline & \multicolumn{4}{|c|}{$\begin{array}{c}\text { Relative change in mortality per } 0.1 \text { unit } \\
\text { decrease in SMR }(95 \% \mathrm{CI})^{*}\end{array}$} \\
\hline \multicolumn{2}{|c|}{$\begin{array}{l}\text { Standardized in-hospital mortality ratio } \\
\text { (SMR), January 2004-June } 2006\end{array}$} & \multicolumn{2}{|c|}{$-3.4 \%(-4.9,-1.9)$} & $<.0001$ \\
\hline Patient-level variables & $\mathbf{N}(\%)$ & In-hospital mortality (\%) & Risk ratio $(95 \% \text { CI })^{*}$ & $P$ value \\
\hline \multicolumn{5}{|l|}{ Age } \\
\hline$<30 \mathrm{~d}$ & $5,878(24.4)$ & 9.0 & Referent & \\
\hline $30 \mathrm{~d}-1 \mathrm{y}$ & $8,700(36.1)$ & 1.9 & $0.31(0.25,0.38)$ & $<.0001$ \\
\hline$>1 \mathrm{y}$ & $9,534(39.5)$ & 0.9 & $0.15(0.12,0.19)$ & $<.0001$ \\
\hline \multicolumn{5}{|l|}{ Race } \\
\hline White & $17,391(72.1)$ & 2.9 & Referent & \\
\hline Black & $3,156(13.1)$ & 3.7 & $1.25(1.03,1.53)$ & .0234 \\
\hline Other & $3,565(14.8)$ & 4.3 & $1.39(1.17,1.64)$ & .0002 \\
\hline \multicolumn{5}{|l|}{ Sex } \\
\hline Male & $13,441(55.7)$ & 3.1 & Referent & \\
\hline Female & $10,671(44.3)$ & 3.4 & $1.18(1.03,1.36)$ & .0158 \\
\hline \multicolumn{5}{|l|}{ Genetic syndrome } \\
\hline No & $20,578(85.3)$ & 3.1 & Referent & \\
\hline Yes & $3,534(14.7)$ & 3.7 & $1.57(1.30,1.90)$ & $<.0001$ \\
\hline \multicolumn{5}{|l|}{ Insurance type } \\
\hline Government & $10,514(43.6)$ & 4.2 & Referent & \\
\hline Private & $8,605(35.7)$ & 2.5 & $0.71(0.61,0.84)$ & $<.0001$ \\
\hline Other & 4,993 (20.7) & 2.3 & $0.73(0.59,0.89)$ & .0022 \\
\hline \multicolumn{5}{|l|}{ RACHS- 1 category } \\
\hline 1 & $2,891(12.0)$ & 1.0 & Referent & \\
\hline 2 & $8,236(34.1)$ & 1.3 & $0.77(0.51,1.16)$ & .2097 \\
\hline 3 & $8,940(37.1)$ & 3.0 & $1.64(1.11,2.42)$ & .0132 \\
\hline 4 & $2,895(12.0)$ & 6.8 & $2.40(1.60,3.61)$ & $<.0001$ \\
\hline 5 or 6 & $1,150(4.8)$ & 15.2 & $3.67(2.41,5.58)$ & $<.0001$ \\
\hline
\end{tabular}

CI, Confidence interval; RACHS-1, Risk Adjustment for Congenital Heart Surgery; *Effect estimates are adjusted for all other variables in the table.

quality improvement efforts and not just expansion efforts. Given the lack of widespread publicly available hospital mortality data, however, this referral system would be challenging to implement. $^{23}$

Of course, creating a referral system based solely on mortality as an outcome measure may not be the best method. There are other important outcome measures that we did not analyze, including but not limited to comorbidities such as ventilation time or infections, cost measures such as length of stay or resource utilization, and patient family factors such as satisfaction with care or perceived quality. Consideration of outcomes in addition to mortality may provide a better model for referral of care. ${ }^{24}$

Our study, which was based on data from a large administrative database, is not without its limitations. First, the use of ICD-9 codes from administrative data has been shown to be valid in identifying cases of congenital heart disease, but it has also been shown to have some falsepositives. ${ }^{25,26}$ Inasmuch as our study included not only diagnosis but also procedure code, we would expect that

TABLE 2. Associations between January 2004-June 2006 hospital surgical case volume and mortality and July 2006-December 2008 patient mortality by RACHS-1 categories

\begin{tabular}{lccccc}
\hline & \multicolumn{2}{c}{ Case volume } & & SMR \\
\cline { 2 - 3 } RACHS-1 category & $\begin{array}{c}\text { Relative change in mortality risk per } \\
\text { increase of 40 cases annually }(\mathbf{9 5} \% \mathbf{C I}) *\end{array}$ & $\boldsymbol{P}$ value & & $\begin{array}{c}\text { Relative change in mortality risk per 0.1 } \\
\text { unit decrease in SMR (95\% } \mathbf{C I}) *\end{array}$ & $\boldsymbol{P}$ value \\
\hline $1,2,3$ & $-1.6 \%(-5.2,2.2)$ & .4122 & & $-2.8 \%(-5.0,-0.7)$ \\
$4,5,6$ & $-14.4 \%(-27.6,1.2)$ & .0678 & & $-2.7 \%(-4.4,-1.0)$ & .0015 \\
\hline
\end{tabular}

$R A C H S$-1, Risk Adjustment for Congenital Heart Surgery; SMR, standardized in-hospital mortality ratio; $C I$, confidence interval. *Effect estimates are adjusted for age, race, sex, genetic syndrome, and insurance type. 
this false-positive rate would have been decreased. Second, our data are limited to in-hospital mortality. The patient who dies of potential surgical complications shortly after discharge from the hospital would not be identified in our data. Death from outpatient surgical complications may be an important factor to consider when analyzing regionalization of operative care. Finally, although the use of data from a large administrative database affords us greater power in our study, comparing mortality rates between individual hospitals may be difficult given limited case volume, a spectrum of severity within RACHS-1 categories, varying surgical approaches to similar lesions across institutions, and improvements in mortality rates over time. ${ }^{27}$ In particular, in-hospital mortality is a relatively rare event, even for hospitals with SMR above the median, and a difference of just 1 or 2 deaths may have a marked impact on the SMR estimates for low-volume hospitals.

\section{CONCLUSIONS}

In this data set, prior hospital surgical volume tended to be associated with improved mortality after higher-risk operations in pediatric patients having surgery for congenital heart disease, whereas prior hospital postoperative mortality was significantly associated with mortality across all risk strata of operations for congenital heart disease. Future research is warranted to evaluate potential quality improvement measures that would allow low-volume hospitals to perform as well as or better than large-volume hospitals.

\section{References}

1. Mushlin AI, Ghomrawi H. Health care reform and the need for comparativeeffectiveness research. N Engl J Med. 2010;362:e6.

2. National Quality Forum. National Quality Forum Web site. Available at: http:// www.qualityforum.org. Accessed Oct 18, 2010.

3. Agency for Healthcare Research and Quality. Agency for Healthcare Research and Quality Web site. Available at: http://www.ahrq.gov. Accessed Oct 18, 2010.

4. Birkmeyer JD, Siewers AE, Finlayson EV, Stukel TA, Lucas FL, Batista I, et al. Hospital volume and surgical mortality in the United States. N Engl J Med. 2002; 346:1128-37.

5. Welke KF, Diggs BS, Karamlou T, Ungerleider RM. The relationship between hospital surgical case volumes and mortality rates in pediatric cardiac surgery: a national sample, 1988-2005. Ann Thorac Surg. 2008;86:889-96; discussion, 896.

6. Bazzani LG, Marcin JP. Case volume and mortality in pediatric cardiac surgery patients in California, 1998-2003. Circulation. 2007;115:2652-9.

7. Checchia PA, McCollegan J, Daher N, Kolovos N, Levy F, Markovitz B. The effect of surgical case volume on outcome after the Norwood procedure. J Thorac Cardiovasc Surg. 2005;129:754-9.
8. Gauvreau K. Reevaluation of the volume-outcome relationship for pediatric cardiac surgery. Circulation. 2007;115:2599-601.

9. Hannan EL, Racz M, Kavey RE, Quaegebeur JM, Williams R. Pediatric cardiac surgery: the effect of hospital and surgeon volume on in-hospital mortality. $\mathrm{Pe}$ diatrics. 1998;101:963-9.

10. Hirsch JC, Gurney JG, Donohue JE, Gebremariam A, Bove EL, Ohye RG. Hospital mortality for Norwood and arterial switch operations as a function of institutional volume. Pediatr Cardiol. 2008;29:713-7.

11. Jenkins KJ, Newburger JW, Lock JE, Davis RB, Coffman GA, Iezzoni LI. In-hospital mortality for surgical repair of congenital heart defects: preliminary observations of variation by hospital caseload. Pediatrics. 1995;95:323-30.

12. Karamlou T, McCrindle BW, Blackstone EH, Cai S, Jonas RA, Bradley SM, et al. Lesion-specific outcomes in neonates undergoing congenital heart surgery are related predominantly to patient and management factors rather than institution or surgeon experience: a Congenital Heart Surgeons Society Study. J Thorac Cardiovasc Surg. 2009;139:569-77. e1.

13. United Healthcare. United Healthcare Web site. Available at: https://www. unitedhealthcareonline.com. Accessed Oct 18, 2010.

14. Rogowski JA, Horbar JD, Staiger DO, Kenny M, Carpenter J, Geppert J. Indirect vs direct hospital quality indicators for very low-birth-weight infants. JAMA. 2004;291:202-9.

15. Kittle K, Currier K, Dyk L, Newman K. Using a pediatric database to drive quality improvement. Semin Pediatr Surg. 2002;11:60-3.

16. Jenkins KJ, Gauvreau K, Newburger JW, Spray TL, Moller JH, Iezzoni LI. Consensus-based method for risk adjustment for surgery for congenital heart disease. J Thorac Cardiovasc Surg. 2002;123:110-8.

17. Zeger SL, Liang KY. Longitudinal data analysis for discrete and continuous outcomes. Biometrics. 1986;42:121-30.

18. Allen SW, Gauvreau K, Bloom BT, Jenkins KJ. Evidence-based referral results in significantly reduced mortality after congenital heart surgery. Pediatrics. 2003; 112(1 Pt 1):24-8.

19. Chang RK, Klitzner TS. Can regionalization decrease the number of deaths for children who undergo cardiac surgery? A theoretical analysis. Pediatrics. 2002;109:173-81.

20. Welke KF, O'Brien SM, Peterson ED, Ungerleider RM, Jacobs ML, Jacobs JP. The complex relationship between pediatric cardiac surgical case volumes and mortality rates in a national clinical database. J Thorac Cardiovasc Surg. 2009; 137:1133-40.

21. Smith PC, Powell KR. Can regionalization decrease the number of deaths for children who undergo cardiac surgery? A theoretical analysis. Pediatrics. 2002;110:849-50; discussion 850.

22. Mavroudis C, Jacobs JP. Congenital heart disease outcome analysis: methodology and rationale. J Thorac Cardiovasc Surg. 2002;123:6-7.

23. Kizer KW. The volume-outcome conundrum. N Engl J Med. 2003;349:2159-61.

24. Clarke DR, Lacour-Gayet F, Jacobs JP, Jacobs ML, Maruszewski B, Pizarro C, et al. The assessment of complexity in congenital cardiac surgery based on objective data. Cardiol Young. 2008;18(Suppl 2):169-76.

25. Strickland MJ, Riehle-Colarusso TJ, Jacobs JP, Reller MD, Mahle WT, Botto LD, et al. The importance of nomenclature for congenital cardiac disease: implications for research and evaluation. Cardiol Young. 2008;18(Suppl. 2): 92-100.

26. Frohnert BK, Lussky RC, Alms MA, Mendelsohn NJ, Symonik DM, Falken MC. Validity of hospital discharge data for identifying infants with cardiac defects. $J$ Perinatol. 2005;25:737-42.

27. Welke KF, Karamlou T, Ungerleider RM, Diggs BS. Mortality rate is not a valid indicator of quality differences between pediatric cardiac surgical programs. Ann Thorac Surg. 2010;89:139-44; discussion, 145-6. 